\title{
The Role of Emergence in Service Systems
}

\author{
Francesco Polese \\ University of Salerno \\ fpolese@unisa.it
}

\author{
Debora Sarno \\ Parthenope University of Naples \\ debora.sarno@uniparthenope.it
}

\author{
Stephen L. Vargo \\ University of Hawaii at Manoa \\ svargo@hawaii.edu
}

\begin{abstract}
It has been recognized that a service systems perspective, informed by service-dominant logic, provides a dynamic approach for studying value cocreation. According to this view, value is the increase in the viability of the system in which actors co-create value. A construct from systems theory-emergence can be of particular interest in contributing to and detracting from systems viability. Emergence is related to the nonlinear interactions characterizing systems' elements that can give rise to novel and unpredictable properties not contained in the elements. This paper relates emergence to service systems based on the service-dominant logic and systems theory literature. Such issues can be useful for service science scholars to identify new research avenues for service systems.
\end{abstract}

\section{Introduction}

It is increasingly being recognized that value cocreation processes cannot be designed, engineered, managed or understood in terms of dyadic, unidirectional and linear provision of goods and "services" from producers to consumers [59], [40]. Instead, a multipart/multilevel, interactional, dynamic and systems view based on service-for-service exchanges is required [62], as pursued by service science (SS) and its foundational mindset of servicedominant logic (S-D logic).

In systems terms, S-D logic defines value as the increase in viability of the system[63], which centers on actors' efforts to find viable interacting conditions in the social environment [4]. Thus, of particular concern is anything that contributes to or detracts from system viability. In this sense, emergence is arguably an essential construct within service science research [62], particularly when considering new technologies and the role played by information. Emergence is a characteristic peculiar to systems since the nonlinear interactions characterizing systems' elements can give rise to emergent properties (entities, structures, concepts, qualities, etc. [8]) that are not contained in the elements (irreducibility), while they are novel and unpredictable [38]. Thus, emergent properties can result in new opportunities for the development and viability of service systems, but being unexpected (making them a particular case of system change [32]) can also cause them to appear as threats [32]. Thus, emergence should be better understood and embraced.

By introducing a focus on the emergent properties of systems, emergence requires a shift systems thinking (the process of thinking using systems ideas [15]). Moreover, many constructs from systems theory (which accept as given the status of systems as things in the world) can be beneficially applied to further delve into emergent properties.

After the analysis of the main insights of emergence in the systems theory literature (Sec. 2), a short overview of service ecosystems and service systems and the importance of emergence to them is provided (Sec. 3 ); then (Sec. 4), the main issues of emergence from systems theory are related to service systems based on the S-D logic and systems theory literature. These issues -- knowledge, adaptation in context, and interactions -can be useful for service scholars to identify new research avenues for service systems, these latter of which are discussed in Sec. 5.

\section{Emergence and systems theory}

The word "system" has Greek roots and means "organized whole". A system can be conceived as "elements in standing relationship" [69], emphasizing the way in which the relationships between the elements are organized and thus the role of every element in such organizations.

Emergence is an important aspect of systems. Although multiple definitions and perspectives on emergence have been provided in the literature, irreducibility seems to be the common denominator, implying that emergent properties have no meaning (or, in other words, cannot be reduced) at the level of the systems' elements [46]. Thus, in ecology, "cloud streets" and "sand ripples" have been considered examples of manifestations of emergent properties. Another common example is water, which shows the wetness property not reducible to the single atoms of 
oxygen and hydrogen. However, many researchers from diverse fields have also incorporated into the definition the concept of novelty, related to features not previously observed in the system [28]. Such a view of novelty results in a discussion about ontological (strong) or epistemological (weak) emergence. Weak emergence is related to the inability to recognize new manifestations of the same fundamental processes in emerging properties due to the currently limited state of observers' knowledge [17]. Conversely, in strong emergence, emergent properties are not deducible, even in principle [14], and their appearance can be considered "a significant evolutionary step in the history of the world" [38]. This is due to dynamic, systemic, and contextual conditions that can never be completely specified [62], as in the common examples of consciousness [38] or markets [62].. Thus, in both weak and strong emergence cases, emergent properties are unexpected, at least with respect to the knowledge of the observers [38].

During the first part of the twentieth century, early system thinkers started to focus their attention on the tension between elements and the whole. They emphasized the importance of properties that emerge at a certain level of complexity and do not exist in lower levels of elements [11]. They acknowledged that the properties of the elements can be understood only at the level of the emergent whole, thus promoting thinking in terms of connectedness, relationships, and context [12]. Over time, starting with the organic biologist von Bertalanffy [69], a methodological scientific approach has developed based on systems. The body of knowledge was enriched by studies of cybernetics, later embraced by the viable system model to support management studies [9]. Sharing some similarities with the viable system model but relying on several other roots and approaches, such as the constructivist one [70], the viable systems approach (VSA) was developed to re-explore the contribution of systems thinking to management and marketing [4],[29],[5]. It can be defined as a meta-theory oriented toward supporting the governance of firms and business dynamics.

In early studies of systems theory, the investigated systems were characterized by linearity and equilibrium seeking [28]. However, complexity and emergence were seriously considered. For example, the hierarchy of complexity of organizations by Boulding [10] ranges from structures exhibiting static behavior (such as crystal structures) to transcendental systems (such as the idea of God). Here, each level presents some emergent properties that cannot be understood based on the theoretical constructs of the lower levels. As a consequence, Boulding highlighted the existence of gaps in knowledge to address the highest hierarchy levels [34].
Later, emergence became a construct of interest in the field of complex systems, with four main schools of research [21]. According to Goldstein [28], complex systems are connoted, among other properties, by nonlinearity and self-organization (adaptability-seeking behavior toward the emergence of a new order). Thus, emergence gained a positive connotation as an orderbringing construct in organizational studies, for example, in the emergence of informal organizations, leadership or networks.

Other authors have highlighted that "the whole emerges from the interactions between the parts, which affect each other through complex network of relationships" [33]. In these cases, researchers were interested in the network of relationships between elements and how they can give rise to the system [33], as well as investigating how different structures have different dynamic consequences and behaviors [58]. These studies - as VSA agrees [29] - were also focused on systems' purposes. Thus, purposefulness itself was considered as an emergent property of a system [16].

\section{Emergence and service systems}

Service systems are configurations of people, technologies, and other resources that interact with others to create mutual value [42] and are studied by SS with a specific focus on design, management, and engineering. This field originated during the same period as S-D logic [63],[65],[66], a mindset based on the assumption that value cannot be obtained in isolation, but it is co-created through resource integration and service exchanges by actors (organizations, individuals, etc.). SS and S-D logic coevolved over time [67], with S-D logic being the conceptual foundation of SS [41]. In S-D logic, systems are conceptualized as service ecosystems in which actors interact, exchanging energy and resources with the environment. According to this view, institutions (laws, norms, practices, symbols, beliefs, etc. [51]) and institutional arrangements assume important roles since they are endogenously generated and provide guidance to and place constraints on actors' behaviors, as presumed in the narrative reported in Figure 1 (loop with blue arrows and green text [65]). The service ecosystem is a more general concept than the service system. Indeed, service systems are primarily focused on technological and informational aspects of value cocreation, and these aspects are captured in both the more general institutions and the institutional arrangements conceptualizations of service ecosystems. Thus, in this paper, S-D logic and service ecosystems are used to inform value co-creation and systems viability in SS [65]. 
According to both S-D logic and SS, service is the application of competencies (such as skills and knowledge) and other resources of an actor for the benefit of another [63], and it is the only reason why actor-to-actor (A2A - [71]) exchanges occur. Moreover, the value co-created by means of interactions is appreciated and perceived differently by every actor who participated in the process, depending on his or her needs, use, and interpretation, as well as the wider context in which the cocreation occurs [40].

Since actors' interactions for resource integration and service exchange occur in service systems, and interactions of elements are the reason for emergent properties [13], emergence must be acknowledged as a characteristic of service systems that can be detected in the realm of institutions and systems [23]. Thus, emergence deserves to be further investigated in service research: when emergent properties are new system's institutions, they change the way in which value is perceived or can be co-created, with unexpected consequences for marketing, management, engineering and design. In these cases, the viability of the ecosystem can be compromised. For example, if new guidelines for the development of electronic medical records in hospitals are unexpectedly introduced, the way in which software houses, physicians and hospital managers act will need to change accordingly, both to grasp new opportunities to increase the viability of their systems (for example, virtually controlling drugs stocks based on patients' consumption reported on electronic medical records) and to avoid the threats of not meeting legislator requirements. However, if the new guidelines are considered a case of weak emergence, they are predictable. Thus, software houses affected by a lack of knowledge of sociopolitical needs will be unprepared, wasting time and resources, while others might not consider emergence as such and, having predicted it, they will be able to co-create value with other actors in the ecosystem.

Emergence has been already introduced in the service ecosystem literature [62], [66]. In Peters [53], attention was paid to the distinction between homopathic (summative) and heteropathic (emergent) types of resource integration and their relationships with value co-creation. Taillard et al. [61] explained how actors' shared intentions can be emergent properties due to actors' interactions. These interactions can give rise to emergent shared institutions and social structures, resulting in the emergence of a service ecosystem. These structures, in turn, can influence actors in the service systems.

This brief overview emphasizes that the construct of emergence is broad and has been analyzed with different perspectives. All of them can be useful for further exploring emergence in service systems, as addressed in the following section.

\section{Embracing emergence in service systems}

Emergent properties are ubiquitous in service systems and are accelerated by the exponential adoption of new technologies, as the unexpected behaviors of humans-machine interactions are enabled and constrained by artificial intelligence, new analytics, etc. [39].

In the following, the main issues related to emergence according to systems' theory resulting from Sec. 2 and 3 are further explored by organizing the discussion around S-D logic concepts. We analyze: (i) actors' knowledge; (ii) systems' adaptation in context; and (iii) actors' interactions. In particular: (i) the knowledge of single actors in understanding emergence is aligned both the concept of weak emergence [17] and a lack of understanding from Boulding [10]); (ii) the adaptation traits of systems are also related to selforganization toward the emergence of a new order [28] in terms of context (institutions and networks) reconfiguration [12]; and (iii) the interactions of actors (for resource integration and service-for-service exchanges) have been claimed by many authors ([13],[38],[61], to cite only some of the references). Although it might be argued that there is no one-to-one mapping of these issues with S-D logic concepts, the classification can support the development of considerations for embracing emergence in service systems. The narrative of S-D logic in the light of emergence (Figure 1) shows that actors engage in resource integration and service for-service exchange, co-creating value; their interactions, enabled and constrained by shared institutions - but also individual agency and knowledge - can give rise to the emergence of irreducible and unexpected properties, fostering (nested) service systems' emergence, dynamics and evolution.

\subsection{The role of actors' knowledge}

As indicated in Sec. 2, there is a philosophical debate on emergence, distinguishing strong from weak emergence. The latter case is an observer relative property and is related to its knowledge, and its cognitive domain is characterized by formal and informal worldviews. Thus, the concept of 'knowledge', which is usually related to the analysis of elements, is here more inclusive and incorporates 'understanding', which in turn is connected to synthesis and the systems approach needed to address emergent properties [49]. In this field, the systems thinker Senge [57] introduced 
mental models, which are conceptual structures in the minds of actors that drive cognitive processes of understanding and influence their actions. The concept has been similarly elaborated by VSA in the information variety model [3], exploding the idea of the requisite variety of Ashby [1]. According to this model, the knowledge of an actor is not the sum of the available information units (data), and the interpretation of information units depends on the structure of the interpretation of the information from each actor. This structure is a "container" in which the perceived information is organized [3], in terms of both interpretation schemes based on experience and categorical values (strong beliefs) that can orient the usage of different interpretation schemes. The model can be used to analyze how actors understand reality and make decisions or to compare actors and assess their structural consonance (compatibility, similarity of information varieties), which can result in successful value co-creation, resonance and increases in systems viability [4]. Moreover, as actors interact, worldviews also interact, and these interactions can be placed in a cognitive domain that drives the purposeful adaptive activity system, co-creating new knowledge [72].

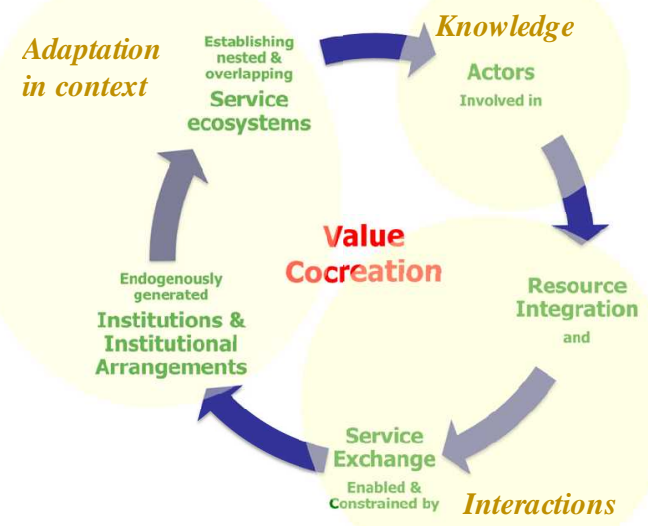

Figure 1. The key elements of emergence and their relationships with the narrative and process of S-D logic (adapted from Vargo and Lusch [65]).

The dependence of weak emergence on the knowledge introduces a further degree of complication in cases in which the observer is part of the system [20], or in other words, the observer can make decisions according to its understanding of the emergent properties. In service systems, this knowledge can be facilitated by the adoption of Collective Knowledge Systems, in which small groups of engaged users cocreate information artifacts that can be used by other users who need information [30]. This co-creation is based on Collective Intelligence logic ("groups of individuals doing things collectively that seem intelligent" [43]) and has been exemplified in the realm of social networks [25]. According to this logic, different microcontributions to the understanding of a phenomenon [50] can multiply, instead of adding to, the intelligence of individuals [37],

Other considerations can derive from the possibility of humans augmenting their computational capability based on simulation models to predict (weak) emergence and to assess counteractions, also based on changes in the actors' information variety and the consequent degree of consonance and possible resonance service-for-service exchanges. Agent Based Simulations have been suggested to constitute a powerful tool to model and analyze the behavior of actors in social systems [56] and service ecosystems, as developed by Fujita et al. [23],[24].

In summary, actors' behaviors (and consequently, service systems dynamics) significantly depend on their knowledge, enabling them to predict weak emergence or face strong emergence. New opportunities to increase knowledge are provided by information and communication technologies. However, T-shaped knowledge [6] - in terms of hard and soft skills - is a necessary, but not sufficient, condition to address emergence.

\subsection{The role of service systems' adaptation in context}

When systems are complex and present functions or purposes, they organize themselves without external direction or control exhibiting emergent behavior [21]. Thus, self-organization is the determinant of emergence but can also result from it. Indeed, the detection of emergence (both weak and strong) in service systems is not related to the need to note a step further in the history of the world but to understand emergent properties and act in accordance with them in an attempt to take advantage or at least avoid disadvantages. Indeed, adaptation within limits in a changing environment is central to systems thinking [15],[16] and systems theories more in general.

Similarly, service ecosystems interacts with their environment [48] in a series of co-creation processes [44], renewing themselves and self-organizing their context.

through changes in institutions [26].[24] Similarly, according to the VSA, the self-organizing response of a viable system to emergence is related to the reconfiguration of the context in terms of relationships. In particular, the changes to the 'structure' of actors' and resources' relationships can be classified as [29]: 
adjustments (elasticity of the structure to the changes based on redundancies); transformation (flexibility of the structure to new configurations); or restructuration (plasticity of the structure with the introduction of new elements taken from the environment and eventual orientation toward new purposes).

Self-organization to and for emergence can be more or less effective due to the context, in terms of institutions in place (shared worldviews, norms, etc.) and networks of relationships (availability and configuration of actors' resources in the network). Moreover, the same characteristics shape the context of emergence.

Since context is fundamental to emergence, and technology is an institutional phenomenon [65] and a tool for achieving institutional change [68], reflections on the role of technology in emergence are particularly interesting for SS. Indeed, SS can play a normative role in enabling, constraining and analyzing value cocreation [54] with the eventual emergence of properties because it leverages both network and process design and technology introduction into service systems.

When emergence is related to context, an interesting point of view that matches these concepts with knowledge was provided by Crutchfield [18], introducing the expression "intrinsic emergence", which is related to the context in which it occurs and the capitalization of such emergence by the system.

In conclusion, service systems' adaptation in context is both a determinant and a result of emergence in a cycling process that describe systems' dynamics. For this reason, autonomous actors, multiple purposes and environment resources should be continuously monitored to assess the self-organization capabilities of service systems and to predict the potential (weak) emergence of new properties toward systems' viability.

\subsection{The role of interactions in actors' resource integration and service-for-service exchanges}

As highlighted in Sec. 3, actors' interactions are foundational to emergence since the interactions of elements can give rise to emergent properties [23]. From a service system perspective, such interactions are manifested through the engagement of actors in resource integration and service-for-service exchange to cocreate value-in-context. Indeed, actors' engagement with its cognitive, behavioral and emotional perspectives - is a microfoundation of value co-creation [60]. Resource integration has already been examined from an emergence perspective, based on the distinction between homopathic and heteropathic resource integration [53]. Indeed, while homopathic resource integration considers only summative relations between resources, the joint action of multiple causes not resulting from the sum of the effects of each of the base resources acting in isolation manifests in the emergence of something new and irreducible to the involved resources [53]. Thus, emergence can clearly be related to creativity, serendipidy [23],[24], etc.. Finally, the service-for-service exchange foundational to interactions in S-D logic can be further justified by emergence when related to evolution. Indeed, as Kauffman and Macready [36] described, co-evolution is "a process of coupled, deforming landscapes where the adaptive moves of each entity alter the landscapes of its neighbours". Co-evolution can be interpreted as the evolution of actors' interactions toward interdependence, and it is configured not as a response to the changing environment (like adaptation) but rather as evolution with it (in terms of other related systems and actors) [47]. Moreover, recalling the sociological view of Thus, actors' co-evolutional intensions, consonance [3] and interdependences should be monitored to predict, detect, and face emergence in service systems.

\section{Discussion}

With the shift in perspective from elements to dynamic systems [12], from producers and consumers to actors' networks and interactions due to service [65], and from technological devices to smart service systems [39], a systems view of value co-creation has become fundamental. Value is the increase in the system viability [63]. However, the complexity of service systems, mainly due to nonlinear contextual interactions between the composing elements, can result in emerging properties [62]. Being unexpected, these properties can enable or create obstacles to value co-creation, thus contributing to or detracting from system viability. As shown in Sec. 2, emergence is not new in systems theories, and its unpredictability and irreducibility to the systems' elements can depend on the observer (which can also be an actor). Given that emergence is ubiquitous, it should be embraced and appreciated, attempting to turn its potential treats into opportunities [32]. In Sec. 4, the main issues of emergence are related to service systems based on the service-dominant logic and systems theory literature to uncover the key leverages available for SS researchers and practitioners. In brief, it has been acknowledged the following: (i) actors' knowledge is both a source of detection of emergence (weak emergence) and a reason for the emergence of new properties through resource integrations, particularly when actors are observing the emerging properties and react/act according to them. Then, actors' knowledge - also in the broader sense of 
synthesis capabilities and holistic views - must be carefully considered when detecting emergence and/or defining strategies to cope with it. Furthermore, Agent Based Simulation can be truly useful to model systems in detecting weak emergence; (ii) adaptation is related to the ability of systems to react to changing conditions (even due to emergence) toward the achievement of certain purposes by leveraging self-organization, as well as with the relationships with the environments. Thus, adaptation is both a determinant and a result of emergence in a cycling process that describes systems' dynamics. Context is particularly important because it provides meaning to value co-creation, giving meaning to emergent properties. Thus, since institutions and actors' networks allow for the adaptation to be more or less effective and can in turn result in emergent properties coming to a new order, they should be designed and engineered carefully in service systems. Moreover, it should be considered that the observers involved in the context (actors) might be more effective in introducing changes. Thus, autonomous actors, multiple purposes and environment resources should be continuously monitored to keep under control the selforganization capabilities of service systems and the potential (weak) emergence of new properties; (iii) actors' interactions are foundational to emergence. Thus, actors' engagement, types of resource integration and co-evolution manifested in service-for-service exchanges are key indicators of emergence. Coevolutional intensions, consonance and interdependences should be monitored to predict, detect, and manage emergence.

Emergence is a fertile construct because it addresses the complexity of reality (instead of analytical and reductionist simplification of it) and the real problems in dealing with service systems.

From a theoretical point of view, further studies are needed to develop these conceptualizations further and explore, for example, the effects of purposes, intentions, engagement, resources, networks, and institutional work on the emergence of new systems' properties and viability. Particular attention should be paid to humanmachine interactions [45] and the consequent emergence of new properties.

In managerial terms, without neglecting reductionism, space should also be given to sense making and synthesis more than to reasoning. T-shaped professionals and organizations are needed to cope with such complexities [6]. Agent Based Simulation and other Modeling and Simulation tools (such as Systems Dynamics) can be adopted to detect weak emergence, as well as to contribute to increasing single actors' knowledge. For example, when emergency is confused with emergence - think, for example, of the underestimation of the symptoms of an epidemic in a hospital - digital games can be used - in the example, distributed by the ministry of healthcare - to educate actors -nurses - with what-if analyses. Monitoring of systems context by means of network and institutional analyses is also important. Reflections on network configurations and possible actions to change them are fundamental to assessing service systems adaptability toward viability. Actors' resources and engagement can also be monitored to detect the potential for heteropathic resource integration. In this sense, given service systems' inner complexity and the potential emergence of new properties, intensions and structural predispositions for co-evolution between actors and other service systems should be always considered in designing, engineering and/or managing systems.

Due to the significant role of context in emergence, the involvement of researchers and managers in context is suggested by adopting case theory [31] as the grounds for theory generation, reporting, conclusions and practical applications related to value co-creation and systems viability.

\section{References}

[1] W.R. Ashby, "Requisite variety and its implications for the control of complex systems", Cybernetica, vol. 1, n. 2, pp. 83-99, 1958

[2] R. Badinelli, S. Barile, I. Ng, F. Polese, M. Saviano, and P. Di Nauta, "Viable service systems and decision making in service management", Journal of Service Management, vol. 23, n. 4, pp. 498-526, 2012.

[3] S. Barile, "The dynamic of informative varieties in the processes of decision making", The 3rd International Conference on Knowledge Generation, Communication and Management, Orlando, Florida, July 10-13, 2009

[4] S. Barile, and F. Polese, "Smart service systems and viable service systems: Applying systems theory to service science", Service Science, vol. 2, n. 1/2, pp. 21-40, 2010

[5] S. Barile, J. Pels, F. Polese, and M. Saviano, "An Introduction on the Viable Systems Approach and its contribution to Marketing", Journal of Business Market Management, vol. 2, pp. 54-78, 2012.

[6] S. Barile, G. Franco, G. Nota, and M. Saviano, "Structure and Dynamics of a "T-Shaped" Knowledge: From Individuals to Cooperating Communities of Practice, Service Science, vol. 4, n. 2, pp. 161-180, 2012.

[7] S. Barile, R. Lusch, J. Reynoso, M. Saviano, and J. Spohrer, "Systems, networks, and ecosystems in service research", Journal of Service Management, vol. 27, Iss. 4, pp. 652-674, 2016 
[8] R. Bhaskar, "Dialectic: The pulse of freedom", Routledge, 2008.

[9] S. Beer, "On heaping our science together", Trappl R., Hanika F., and Tomlinson R. (eds.), Progress in Cybernetics and Systems Research, vol. II, John Wiley, NY, pp. 3-11, 1975.

[10] K.E. Boulding, "General systems theory-The skeleton of science", Management Science, vol. 2, pp. 197208,1956

[11] C.D. Broad, The mind and its place in nature, Routledge and Kegan Paul, London, 1925.

[12] F. Capra, The Web of Life: A new scientific Understanding of Living Systems, Anchor, Doubleday Books, New York, 1996.

[13] J.L. Casti, Complexification: Explaining a paradoxical world through the science of surprise; Harper Perennial: New York, 1995.

[14] D.J. Chalmers, "Strong and weak emergence", Clayton P., Davies P. (eds.) The re-emergence of emergence. The emergentist hypothesis from science to religion, vol. 11, pp. 244-256, 2006.

[15] P.B. Checkland, System Thinking, system practice, John Wiley and Sons, England, 1981.

[16] P. Checkland "Soft Systems Methodology: A Thirty Year Retrospective", Systems Research and Behavioral Science, vol. 17, pp. S11-S58, 2000.

[17] P. Clayton, "Conceptual foundations of emergence theory", Clayton, P., Davies P. (eds.), The re-emergence of emergence (pp. 1-34). Oxford: Oxford University Press, 2006.

[18] J.P. Crutchfield, "Is Anything Ever New? Considering Emergence", Cowan G., Pines D., and Melzner D. (eds.), Integrative Themes, Addison-Wesley, Reading, MA, pp.1-15, 1994.

[19] T.W. Deacon "Emergence: The hole at the Wheel's Hub", Clayton P., Davies P. (eds.), The re-emergence of emergence. The emergentist hypothesis from science to religion, vol. 5, pp. 111-150, 2006.

[20] J. de Haan "How emergence arises", Ecological Complexity, vol. 3, n. 4, pp. 293-301, 2006.

[21] T. De Wolf, and T. Holvoet, "Emergence and SelfOrganisation: a statement of similarities and differences", Lecture Notes in Artificial Intelligence, SpringerVerlag, pp. 96-110, 2004

[22] P. DiMaggio, and W. Powell, "The Iron Cage Revisited: Institutional Isomorphism and Collective Rationality in Organizational Fields" American Sociological Review, vol. 48, n. 2, pp. 147-160, 1983.
[23] S. Fujita, C. Vaughan, and S.L. Vargo, "Service Ecosystem Emergence from Primitive Actors in Service Dominant Logic: An Exploratory Simulation Study", Proceedings of the 51st Hawaii International Conference on System Sciences, pp. 1601-1610, 2018.

[24] S. Fujita, C. Vaughan, and S.L. Vargo, "Service Ecosystems Emergence and Interaction: A simulation Study", Proceedings of the 52nd Hawaii International Conference on System Sciences, pp. 1926-1935, 2019.

[25] M. Gaeta, F. Loia, D. Sarno, and L. Carrubbo, "Online Social Network Viability: Misinformation Management Based on Service and Systems Theories", International Journal of Business and Management, vol. 14, n. $1,2019$.

[26] A. Giddens, Central Problems in Social Theory: Action, Structure and contradiction in social analysis, University of California Press, CA, 1979.

[27] A. Giddens, The constitution of society: Outline of the structuration theory, Cambridge Press, 1984.

[28] J. Goldstein, "Emergence as a Construct: History and Issues", vol. 1, pp. 49-72, 1999.

[29] G.M. Golinelli, Viable Systems Approach (VSA). Governing Business Dynamics, Cedam, Italy, 2010.

[30] T. Gruber, "Collective knowledge systems: Where the Social Web meets the Semantic Web", Web Semantics: Science, Services and Agents on the World Wide Web, vol. 6, n.1, pp. 4-13, 2008

[31] E. Gummesson, Case theory in business and management, SAGE Publications, London, 2017.

[32] P. Holman, Engaging Emergence. Turning Upheaval into Opportunity, Better-Koehler Publisher, 2010.

[33] M.C. Jackson, "Systems Thinking: Creative Holism for Managers", University of Hull, UK, John Wiley \& Sons, 2003.

[34] M.C. Jackson, "Fifty years of systems thinking for management", Journal of the Operational Research Society, vol. 60, n. sup1, S24-S32, 2006.

[35] E. Jantsch, The self-organizing universe, Pergamon, 1980.

[36] S. Kauffman, and W. MacReady, "Technological evolution and adaptive organizations", Complexity, vol. 1, n 2, pp. 26-43, 1995.

[37] D. Kerckhove, The Skin of Culture, Somerville Press, Ireland, 1995. 
[38] J. Kim, "Making Sense of Emergence", Philosophical Studies, vol. 95, pp. 3-36, 1999.

[39] C. Lim, and P.P. Maglio, "Clarifying the Concept of Smart Service System" Maglio P., Kieliszewski C., Spohrer J., Lyons K., Patrício L., Sawatani Y. (eds.), Handbook of Service Science, Volume II, Service Science: Research and Innovations in the Service Economy. Springer, Cham, 2019.

[40] R.F. Lusch, and S.L. Vargo, Service-Dominant Logic: Premises, Perspectives, Possibilities, Cambridge University Press, New York, NY, 2014.

[41] P.P. Maglio, and J. Spohrer, "A service science perspective on business model innovation", Industrial Marketing Management, vol. 42, pp. 665-670, 2013.

[42] P.P. Maglio, S.L., Vargo, N. Caswell, and J. Spohrer, "The service system is the basic abstraction of service science", Information Systems and e-business Management, vol. 7, pp. 395-406, 2009.

[43] T.W. Malone, R. Laubacher, and C. Dellarocas "The Collective Intelligence Genome", MIT Sloan Management Review, vol.51, n. 3, pp. 21-30, 2010.

[44] M. McLuhan, and Q. Fiore, The medium is the message, Gingko Press, Berkeley, CA, 1996.

[45] A. Medina-Borja, "Embedding Humans into Service Systems Analysis: The Evolution of Mathematical Thinking About Services", Maglio P., Kieliszewski C., Spohrer J., Lyons K., Patrício L., Sawatani Y. (eds.), Handbook of Service Science, Volume II. Service Science: Research and Innovations in the Service Economy, Springer, Cham, 2019.

[46] E. Meron, "Pattern-formation approach to modelling spatially extended ecosystems", Ecological Modelling, vol. 234, pp. 70-82, 2012.

[47] E. Mitleton-Kelly, "Ten Principles of Complexity and Enabling Infrastructures", Mitleton-Kelly E. (ed.), Complex Systems and Evolutionary Perspectives on Organizations: The Application of Complexity Theory to Organizations. Pergamon, Amsterdam, Chap. 2, pp. 23-50, 2003.

[48] J.F. Moore, The death of competition: Leadership and strategy in the age of business ecosystems, HarperCollins, New York, NY, 1996.

[49] P. Morgan, "The idea and practice of Systems Thinking and their relevance for capacity development", European Centre for Development Policy Management, 2005.

[50] M. Nielsen, Reinventing Discovery: The New Era of Networked Science. Princeton University Press, 2011.

[51] D.C. North, Institutions, Institutional Change and Economic Performance. Cambridge University Press, Cambridge, UK, 1990.
[52] T. O'Connor, "Emergent properties", American Philosophical Quarterly, vol. 31, pp. 97-98, 1994.

[53] L.D. Peters, "Heteropathic versus homopathic resource integration and value co-creation in service ecosystems", Journal of Business Research, vol. 69, n. 8, pp. 2999-3007, 2016.

[54] F. Polese, "Successful Value Co-creation Exchanges: A VSA contribution", Barile S., Pellicano M., Polese F. (eds.), Social Dynamics in a Systems Perspective, New Economic Windows, pp. 19-37, Springer, Cham, 2018.

[55] F. Polese, J. Pels, B. Tronvoll, R. Bruni, and L. Carrubbo, "A4A relationships", Journal of Service Theory and Practice, vol. 27, n. 5, pp. 1040-1056, 2017.

[56] R.K. Sawyer, "The Science of Social Emergence", Trajkovski G. Collins S. (eds.), Handbook of Research on Agent-Based Societies: Social and Cultural Interactions, pp. 1-16. IGI Global, Hershey, PA, 2009.

[57] P. Senge, The Fifth Discipline: The Art and Practice of the Learning Organization, 1990.

[58] P. Senge, "Comments on Illuminating the blind spot: leadership in the context of emerging worlds", http://www.dialogonleadership.org/SengeComment.html, 2001.

[59] J. Spohrer, and S.K. Kwan, "Service science, management, engineering, and design (SSMED): an emerging discipline--outline and references", International Journal of Information Systems in the Service Sector, vol. 1, n. 3, p.1, 2009.

[60] K. Storbacka, R.J. Brodie, T. Böhmann, P.P. Maglio, and S. Nenonen, "Actor engagement as a microfoundation for value co-creation", Journal of Business Research, vol. 69, n. 8, pp.3008-3017, 2016.

[61] M. Taillard, L.D.Peters, J. Pels, and C. Mele, "The role of shared intentions in the emergence of service ecosystems", Journal of Business Research, vol. 69, pp. 29722980, 2016.

[62] S.L. Vargo, "Service-Dominant Logic: Back and Forward", The SAGE Handbook of Service-Dominant Logic. Vargo S.L., Lusch R.F. (eds.), ch. 41, pp. 720-739, 2018.

[63] S.L. Vargo, and M.A. Akaka, "Value Cocreation and Service Systems (Re)Formation: A Service Ecosystems View", Service Science, vol. 4, n. 3, pp. 207-217, 2012.

[64] S.L. Vargo, and R.F. Lusch, "Service-dominant logic: continuing the evolution", Journal of the Academy of marketing Science, vol. 36, n.1, pp. 1-10, 2008. 
[65] S.L. Vargo, and R.F. Lusch, "Institutions and axioms: an extension and update of service-dominant logic", Journal of the Academy of Marketing Science, vol. 44, n. 1, pp. 5-23, 2016.

[66] S.L. Vargo, and R.F. Lusch, "Service-dominant logic 2025", International Journal of Research in Marketing, vol. 34, pp. 46-67, 2017.

[67] S.L. Vargo, R.F. Lusch, and M.A. Akaka, "Advancing Service Science with Service-Dominant Logic", Maglio P., Kieliszewski C., Spohrer J. (eds) Handbook of Service Science. Service Science: Research and Innovations in the Service Economy. Springer, Boston, MA, 2010.

[68] S.L. Vargo, H, Wieland, M.A. Akaka, "Innovation through institutionalization: A service ecosystems perspective", Industrial Marketing Management, vol. 44, pp. 63-72, 2015.
[69] L. von Bertalanffy, General System Theory Foundations, Development, Applications, Harper, New York, NY, 1968.

[70] E. von Glasersfeld, "The radical Constructivist view of science", Foundations of Science, vol. 6, n. 1-3, pp. 31-43, 2001.

[71] H. Wieland, F. Polese, S.L. Vargo, and R.F. Lusch, "Toward a Service (Eco)Systems Perspective on Value Creation", International Journal of Service Science, Management, Engineering and Technology, vol. 3, Jul-Sep., n. 3, pp. 12-24, 2012.

[72] M. Yolles, "Organisations, complexity, and viable knowledge management”, Kybernetes, vol. 29, iss. 9/10, pp.1202-1222, 2000. 